\title{
Family Medicine and Community Health \\ Suspected cases of COVID-19: study protocol for reporting characteristics and the outcomes
}

\author{
Ehab Hamed (D), Mohamed Abd Elhamid, Bayan Alemrayat
}

To cite: Hamed E, Abd Elhamid M, Alemrayat B. Suspected cases of COVID-19: study protocol for reporting characteristics and the outcomes. Fam Med Com Health 2020;8:e000400. doi:10.1136/ fmch-2020-000400

Check for updates

(c) Author(s) (or their employer(s)) 2020. Re-use permitted under CC BY-NC. No commercial re-use. See rights and permissions. Published by BMJ.

Qatar University Health Centre, Primary Health Care Corporation, Doha, Qatar

Correspondence to Dr Ehab Hamed; Dr.ehabaziz@gmail.com

\section{BACKGROUND}

While research and reporting on COVID-19 disease focused on laboratory-confirmed cases, many suspected COVID-19 cases are advised to home isolate based on symptoms and risk factors and not on laboratory test findings. While guidance suggests that primary care physicians must rely on their clinical judgement for evaluation of those cases, there has been no risk stratifying tool that has been reported or validated in this cohort of patients. This reflection note reviews current guidance, identifies gaps in our knowledge and clinical practice and finally provides a rationale for research in this cohort of patients. We propose a research design with detailed descriptions of variables that would be feasible to examine in primary care settings. Primary care research in the characteristics and the outcomes of suspected cases of COVID-19 may provide a different view on the COVID-19 epidemic. We hypothesise that most of the patients with suspected diagnosis and home isolation will have good outcomes. Reporting on the characteristics and the outcomes in this cohort of patients may provide hope to patients and to the international community that receives daily updates on confirmed cases and mortality rates but none on the recovery counts.

Severe acute respiratory syndrome coronavirus 2 (SARS-CoV-2; COVID-19) virus is a member of the coronaviruses, which is closely related to SARS-CoV virus. Common signs on presentation include fever, cough and shortness of breath. ${ }^{1}$ Supportive care is the mainstay of treatment with no specific antiviral treatment. While the disease could be asymptomatic or mild in many cases, moderate cases require hospitalisation, and severe cases need the support of vital organ functions.

WHO advised suspecting COVID-19 in patients with acute fever and $\geq 1$ sign or symptom of the respiratory disease combined with a risk factor for exposure. Exposure risk factors included recent travel to infected areas or those who had direct contact with cases within 14 days of the start of their symptoms. The term 'Probable case' recently expanded to include a suspect case for whom testing could not be performed for any reason. 'Confirmed cases' is a term that is reserved only for those with laboratory confirmation irrespective of the presence or absence of clinical symptoms. ${ }^{2}$

At the start, WHO advised screen and triage, all suspected cases who had mild symptoms had a COVID-19 PCR test. ${ }^{3}$ Patients with positive results were advised quarantine in either home or quarantine facilities dependant on local guidance. Later with the strain on resources, guidance was updated. Centers for Disease Control and Prevention (CDC) and many countries updated guidance to advise home isolation with no testing for suspected cases with mild symptoms. Testing for COVID-19 virus is now reserved for severe presentation or high-risk population dependant on the local guidelines.

CDC provided prioritisation criteria for testing. The priority-1 population included patient requiring hospitalisation. Priority-2 population include patients older than 65 years of age, with comorbid conditions, in long-term facilities and first responders with symptoms. ${ }^{45}$ Suspected and probable cases with mild symptoms and that are not deemed as a priority case for testing will be advised to home isolate for 14 days with remote follow-up and safety netting. CDC guidance advises clinician to use clinical judgement to decide whether a patient should be tested for COVID-19 or not. The new guidance created a new cohort of patients with diagnosis based on the risk of exposure and symptoms but no laboratory confirmation. To our knowledge, there is little reporting on outcomes in this cohort of patients. 


\section{CLINICAL JUDGEMENT IN PNEUMONIA AND SEPSIS CASES}

While current guidance advises on using clinical judgement, we noticed that all the tools for evaluation of respiratory tract infection were designed and validated for usage in accident and emergency (A\&E) or hospital settings and not primary care settings. The design included many parameters that are not available to general practice and validation happened in a different cohort of patients which makes unreliable in primary healthcare settings.

Validated clinical judgement tools to discharge or admit patients with respiratory tract infection in A\&E and hospital settings include:

1. Pneumonia Severity Index/PORT Score estimates mortality for adult patients with community-acquired pneumonia. ${ }^{67}$

2. CURB-65 Score estimates mortality of communityacquired pneumonia to help determine inpatient versus outpatient treatment. ${ }^{78}$

3. MuLBSTA Score predicts 90-day mortality in patients with viral pneumonia. ${ }^{9}$

4. SMART-COP Score for Pneumonia Severity predicts the need for intensive respiratory support in communityacquired pneumonia. ${ }^{10}$

5. SIRS defines the severity of sepsis and septic shock criteria. ${ }^{11}$

6. Quick SOFA (qSOFA) identifies high-risk patients for in-hospital mortality with suspected infection outside the intensive care unit. ${ }^{12}$

All tools were designed primarily to predict admission to intensive treatment unit (ITU) or mortality in pneumonia or sepsis. They are used clinically to inform management decisions. Most targeted mainly bacterial infections; only MuLBSTA were explicitly designed for viral pneumonia. Indeed, most of them are quite complicated to implement in primary care settings with the simplest of those scores that could be readily applicable is qSOFA Score.

The scores list investigations are not readily available to primary healthcare providers, for example, arterial blood gases results. Availability of investigations as simple as complete blood count or X-ray findings varies from one healthcare settings to another. Investigations in mild cases could just be merely inappropriate based on the benefit-to-harm ratio. General practitioners and primary care providers in most cases form a clinical judgement based on history, medical history data and necessary vital observations.

Though most of those scoring tools were designed and validated in different settings, the elements of those tools may help to identify essential health determinants that had an impact on outcomes in patients with infection and/or pneumonia. Those determinants could be used to inform variables that would need to be examined for associations in presentations in primary care settings.

National Institute for Health and Care Excellence (NICE) issued guidance for managing suspected or confirmed cases in the community advised minimising face-to-face consultations and limited examination unless necessary. Limited examination means that auscultation is not essential, and blood pressure measurement should be considered if it will contribute to a change in decisionmaking. ${ }^{13} 14$ Rapid diagnosis of pneumonia could be made based on confusion, temperature, respiratory rate and heart rate, which are the clinical observations that are readily available to primary healthcare professionals.

NICE advised using different tools to assess severity; those include CRB65, MRC Dyspnoea Scale and National Early Warning Score (NEWS2 tool) to assess severity. ${ }^{15}$ CRB65 was previously validated in primary healthcare settings while NEWS2 tool was not. ${ }^{16-18}$ Both of which have not been validated in patients with suspected COVID-19 infection.

\section{REPORTING OUTCOMES OF CONFIRMED CASES BUT NOT SUSPECTED/PROBABLE CASES}

In the scenario of COVID-19, the top priority is to isolate the case; keeping the patient in the healthcare facility for further simply defies that purpose. Many primary healthcare providers now diagnose those patients using remote consultation or telemedicine, where even the simplest form of investigations is not available.

In confirmed cases, WHO's revised case reporting form for COVID-19 specifies clinical points to report and outcomes; the tool is designed to monitor and report cases to WHO. ${ }^{19}$ These data help to inform planning but misses out on reporting in all suspected or probable cases.

The form again highlights relevant health domains, specifically medical history and defines clear outcomes that could be similarly used for reporting suspected cases. While the focus on reporting and testing understandably focuses on patients who require hospitalisation, little information and outcome reporting occurred in primary healthcare on national and international levels.

Current COVID-19 practice of advising suspected and probable mild cases for home isolation for 14 days is warranted based on the scale of the epidemic. Classification of those cases to mild, moderate and severe is dependent on subjective assessment which in some cases might be remote. General practitioners and primary healthcare providers are well acquainted with uncertainties.

Much is needed though to describe demographics and clinical characteristics of those patients who are advised to home isolate, their disease outcomes and possible associations with their premorbid conditions. To our knowledge, there is no publication to date to report national and international healthcare systems suspected or probably suspected cases and their outcome. Designing research studies to report on the number of suspected and probable cases, their demographic and health characteristics and describing disease outcomes may be a research priority that is currently overlooked.

This research ideally would also explore the association with comorbidities in a milder form of presentations and admission to hospital and ITU as a possible outcome. The data may form the backbone for a risk stratification 
model to inform the clinical decision in primary healthcare settings or be used to validate CRB65 and NEWS2 tools in this cohort of patients.

\section{RESEARCH SUGGESTION}

Based on the previously mentioned factors, we would like to propose a historical cohort study design to report on patient characteristics and outcomes in patients with a suspected or probable case of COVID-19 to be adapted to local settings depending on the local guidelines and availability of data.

\section{Study objectives}

Primary

1. Report on the outcome of home isolation in suspected and probable cases of COVID-19.

2. Analyse the characteristics of those patients who were identified as possible suspects of COVID-19 and were advised for home isolation in Qatar.

Secondary

1. Examine associations between those demographic and clinical determinants and defined outcomes.

The study will follow them up to the time of admission with COVID as a diagnosis or 14 days of home isolation.

\section{Study design}

A cohort (prospective or historic) observational study.

\section{Sampling}

As feasibly possible.

\section{Settings}

Primary healthcare settings.

\section{Population}

Inclusion criteria include

1. Diagnosis with suspected SARS (severe acute respiratory syndrome)/COVID19 diagnosis during the pandemic period (who were subjected to home isolation precaution with or without testing).

Suspected and probable cases terminology encompass cases with fever or upper respiratory tract infection (URTI) and one risk factor of contracting the disease. Risk factors include a direct contract with a confirmed case or had travelled to an endemic area or high-risk population like healthcare professionals.

\section{Intervention/investigation}

We would like to propose multiple variables to examine, based on the following criteria for inclusion:

1. The revised clinical case report for COVID-19 developed by WHO.

2. The different scores previously validated in other settings to indicate poor outcomes.

3. The limitation of possible investigations available in primary healthcare settings.
Independent variables to report may include patients' demographics and characteristics, medical history and vital signs.

\section{Comparison}

No comparison group.

\section{Outcome}

As per WHO revised reporting form to standardise outcome measures

1. Admission to hospital with SARS/COVID diagnosis and time to admission in days (Yes-No-Unknown) if yes (Date).

2. Results of laboratory test for COVID-19 (positive-negative-unknown).

3. Requires oxygen.

4. Admission to ITU (Yes-No-Unknown)-if yes (Date).

The outcome should be reported up to 30 days from the first presentation in line with WHO report.

\section{LIMITATIONS AND ASPIRATIONS}

One limitation of such a study is that it will be inclusive of all URTI infections with fever and URTI. It will miss out on cases who are asymptomatic. Unless nationally designed, it may miss out on patients presenting to secondary care and private healthcare providers. It is essential to highlight that testing as the gold standard of diagnosis at this stage, nasopharyngeal swab, has its limitations. False-negative results are not uncommon and may be missing on as much as $30 \%-35 \%$ of cases. Causes of false negative include low viral load early in the disease, issues with sample collection and issues with handling and shipping. ${ }^{20}$

The much-needed research is required to provide further insights into the scale of the epidemic; outcomes in those patients we advise to home isolate as suspects are not reported to date. We hypothesise that admission and mortality rate in those group of patients is low. The data may provide hope to those we sent home with suspected or probable diagnosis and more importantly to the international community that receives daily updates on confirmed cases and mortality rates but very minimal on the recovery counts. The study results, if proves to have a positive outcome, should not be confused with the definite recovery rates of COVID-19 and should not be used to advise the patient not to stay at home but rather to instil hope into higher rates of recovery and low rates of admission in population with mild symptoms at the time of the epidemic.

\section{Collaborators Dr Ahmed Sameer Alnuaimi.}

Contributors All authors have discussed the planning and the framework of the reflection notes. All designed the theoretical framework and reviewed the literature and wrote the report.

Funding The authors have not declared a specific grant for this research from any funding agency in the public, commercial or not-for-profit sectors. 
Competing interests Kindly note that we added BA as a coauthor in your study following the review and approval of all authors.

Patient consent for publication Not required.

Provenance and peer review Not commissioned; internally peer reviewed.

Open access This is an open access article distributed in accordance with the Creative Commons Attribution Non Commercial (CC BY-NC 4.0) license, which permits others to distribute, remix, adapt, build upon this work non-commercially, and license their derivative works on different terms, provided the original work is properly cited, appropriate credit is given, any changes made indicated, and the use is non-commercial. See: http://creativecommons.org/licenses/by-nc/4.0/.

ORCID iD

Ehab Hamed http://orcid.org/0000-0002-4404-1424

\section{REFERENCES}

1 Coronavirus Disease 2019 (COVID-19) | CDC [Internet] [cited 2020 Mar 29]. Available: https://www.cdc.gov/coronavirus/2019-ncov/ index.htm

2 Global Surveillance for human infection with coronavirus disease (COVID-19) [Internet] [cited 2020 Mar 29], 2020. Available: https:// www.who.int/publications-detail/global-surveillance-for-humaninfection-with-novel-coronavirus-(2019-ncov)

3 Clinical management of severe acute respiratory infection (SARI) when COVID-19 disease is suspected V1.2. [Internet] [cited 2020 Mar 30], 2020. Available: https://www.who.int/publications-detail/homecare-for-patients-with-suspected-

4 Interim Guidance: Healthcare Professionals 2019-nCoV | CDC [Internet] [cited 2020 Mar 29]. Available: https://www.cdc.gov/ coronavirus/2019-ncov/hcp/clinical-criteria.html?CDC_AA_refVal= https\%3A\%2F\%2Fwww.cdc.gov\%2Fcoronavirus\%2F2019-ncov\% 2Fclinical-criteria.html

5 Priorities for testing patients with suspected COVID-19 infection.

6 Fine MJ, Auble TE, Yealy DM, et al. A prediction rule to identify lowrisk patients with community-acquired pneumonia. $N$ Engl J Med 1997;336:243-50.

7 Shah BA, Ahmed W, Dhobi GN, et al. Validity of pneumonia severity index and CURB-65 severity scoring systems in community acquired pneumonia in an Indian setting.
8 Lim WS, van der Eerden MM, Laing R, et al. Defining community acquired pneumonia severity on presentation to hospital: an international derivation and validation study. Thorax 2003;58:377-82.

9 Guo L, Wei D, Zhang X, et al. Clinical features predicting mortality risk in patients with viral pneumonia: the MuLBSTA score. Front Microbiol 2019;10:2752.

10 Charles PGP, Wolfe R, Whitby M, et al. Smart-Cop: a tool for predicting the need for intensive respiratory or vasopressor support in community-acquired pneumonia. Clin Infect Dis 2008;47:375-84.

11 Levy MM, Fink MP, Marshall JC, et al. 2001 SCCM/ESICM/ACCP/ ATS/SIS International Sepsis Definitions Conference. In: Critical care medicine, 2003: 1250-6.

12 Seymour CW, Liu VX, Iwashyna TJ, et al. Et alassessmentnt of clinical criteria for sepsis for the third international consensus definitions for sepsis and septic shock (sepsis-3). JAMA - J Am Med Assoc 2016;315:762-74.

13 COVID-19 rapid guideline: managing suspected or confirmed pneumonia in adults in the community (NG165) [Internet] [cited 2020 Apr 5], 2020. Available: https://www.nice.org.uk/guidance/ ng165/resources/covid19-rapid-guideline-managing-suspectedor-confirmed-pneumonia-in-adults-in-the-community-pdf66141902429125

14 Pluddemann A, Hobbs R, Mahtani KR, et al. Rapid diagnosis strategy of community-acquired pneumonia for clinicians [Internet] [cited 2020 Apr 5]. Available: https://www.nice.org.uk/guidance/cg191/ chapter/1-

15 Gough J. The pathological diagnosis of emphysema. Proc $R$ Soc Med 1952;45:576-7.

16 Ahrq. Community-acquired pneumonia in the primary care setting background on community-acquired pneumonia [Internet]. [cited 2020 Apr 5]. Available: http://www.cdc.gov/

17 National Early Warning Score (NEWS) 2 | RCP London [Internet] [cited $2020 \mathrm{Apr}$ 5], 2017. Available: https://www.rcplondon.ac.uk/ projects/outputs/national-early-warning-score-news-2

18 Marchello CS, Ebell MH, Dale AP, et al. Signs and Symptoms That Rule out Community-Acquired Pneumonia in Outpatient Adults: A Systematic Review and Meta-Analysis. [cited 2020 Apr 5]. Available: http://www.jabfm.org

19 Revised case report form for confirmed novel coronavirus COVID-19 (report to WHO within 48 hours of case identification) 2020.

20 Fact sheet for healthcare providers CDC-2019-nCoV real-time RT-PCR diagnostic panel [Internet] [cited 2020 Mar 29]. Available: https://www.accessdata.fda.gov/scripts/medwatch/index.cfm? action=reporting.home 